\author{
János Fritz
}

\title{
Komitat Somogy im Spiegel der Angaben der landwirtschaftlichen Betriebszählung vom Jahre 1935.
}

\begin{abstract}
Purpose of the study. The study aims to present the most important findings of the analysis of the 1935 agricultural census in Somogy county, referring to the local solutions to the economic crisis. The situation in Somogy was unique since the county's weight, dominated by large estates, increased in the Hungarian agricultural policy as the result of the Treaty of Trianon. Moreover, as leaders of national advocacy organizations, local agricultural leaders became key shapers of agricultural policy in these decades. Thus, an important question is to what extent the census' data examined reflected the dominant role of these large landowners.

Applied method. The study analyses statistical data and uses the method of historical comparison. Specifically, the 1935 Somogy County census data were analyzed and compared with the census data of 1895 . The results thus obtained were compared with Somogy related conclusions of Kiss Albert's work.

Outcomes. One of the main objectives of the agricultural census carried out at the same time as the surveys of other countries was to test the impact of land reform that had recently been completed. On the other hand, the census was at some level part of the crisis management mechanism of the time, where intensification was the only way out of the agricultural crisis. Although this county was mainy dominated by large estates in the country, this is true even if we know from the analysis that by 1935 the proportion of large estates had decreased compared to the data of the 1895 survey. However, this decrease was not so much due to land reform, but rather to parcels and the increasing number of small leases. Somogy was in the middle in terms of intensification of agriculture, based on the national ranking. Although the division of labour and cooperation between large and small enterprises was becoming more and more common here, at that time, contrary to economic considerations, it was not yet possible completely get rid off the endevour of self-sufficiency on farms.
\end{abstract}

Keywords: agricultural census, economic crisis, land reform, intensification, small rent

\section{Einführung}

In dieser Studie ging ich - im Zusammenhang mit meiner kurz vorher geschehenen Verteidigung der Doktorarbeit - nicht auf die wichtigsten Ergebnisse des Agrarzensus vom Jahre1935 im Komitat Somogy ein. Aber warum sollte sich ein Volkswirt oder ein Historiker für dieses Thema interessieren? Nur deshalb, weil diese Konskription gewissermaßen einen Grund zur Behandlung der Wirtschaftskrise von 1929 geleistet hat. Geradeso, wie vorher auch der Zensus von 1895 die Zustände der Landwirtschaft nach der Getreidenkrise gezeigt hat. Also Die Aufnahme passte sich in irgendwelcher Weise in den Mechanismus der damaligen Krisenbekämpfung ein.

Die Agrarstatistikerin Frau Sándor Laczka schrieb in einer ihrer Studien vom Jahre 2000, dass der Zensus eigentlich aufgedeckt hat, wie rückständig die ungarische Agrarwirtschaft im internationalen Kontext derzeit gewesen ist. Die Erhebung aus dem Jahre 1935 war die Erste, welche den Zusammenhang mit den Erhebungen anderer Länder betrachtet und sich so in ihrer Abwicklung unterschied. Das ganze Projekt wurde von der Vorgängerorganisation 
der FAO, des Internatinonalen Landwirtschaftsinstituts von Rom koordiniert. Es ist wichtig hervorzuheben, dass die Angaben damals in fünf Bänden veröffentlicht worden sind. ${ }^{1}$

Was die Somogyer Ergebnisse betrifft, bin ich offensichtlich nicht der Erste, der diese analysiert hat. Vor mir haben es schon andere Heimatforscher getan, wie József Kanyar in den Achtzigerjahren ${ }^{2}$, István Király in den Neunzigerjahren, oder schon eher. ${ }^{3}$ Was kann ich dieser Sache hinzufügen? In meiner Dissertation erforschte ich grundsätzlich den Fragenkreis der Groß- und Kleinbetriebe. Aus diesem Blickwinkel betrachte ich auch das gegebene Segment.

\section{Die Umstände der landwirtschaftlichen Betriebszählung}

Vor allem betrachten wir das politische und fachliche Umfeld, in welchem der Zensus von 1935 abgewickelt wurde. Zuerst muss hier mit der Krisenbehandlung angefangen werden. Diese Maßnahmen werden mit dem Namen von Gyula Gömbös verknüpft, können jedoch eher dem Finanzminister Béla Imrédy zugeschrieben werden, der zugleich die Funktionen eines wirtschaftlichen Spitzenminister ausübte. Innerhalb dieses Maßnahmenbündels bildete die Lösung der Schuldenfrage der Landwirte einen wichtigen Teil. Imrédy erkannte, dass diese Schulden den normalen Kreditverhältnissen enthoben und in besonderer Weise behandelt werden mussten. Im Oktober 1933 tritt der Ministerialerlass mit der Nummer 14000/1933. in Kraft, der den Landwirtenschutz einführte. Diese Anordung hat nach der Meinung des Pressenchefs István Antal den größten Erfolg der Gömbös-Regierung bedeutet und hat im großen Maße zu deren Stabilisierung beigetragen. ${ }^{4}$ Im Übrigen hat man mit dem Zensus von 1935 danach gestrebt die sogenannten „geschützten Güter” aufzumessen und zugleich auch die Felder zu registrieren, die mit der - im Jahre 1928 abgeschlossenen - Bodenreform zugeteilt worden waren. (Bei den Ersteren bedeutete der "Schutz”, dass die Gläubiger gegen sie zwei Jahre lang keine Vollstreckung beantragen durften.)

Was den statistischen Apparat betrifft: das Statistische Zentralamt (KSH) wurde im Jahre 1921 neugegründet. Zwar wurde im März 1933 ein Plan über die Konskription der Liegenschaften und landwirtschaftlichen Betriebe vor dem Parlament unterbreitet, aber es konnte damals wegen der schlechten finanziellen Lage des Landes keine Gesetzeskraft erlangen. Zuletzt trafen die Maßnahmen des Ministerialerlasses mit der Nummer 1111/1935., der mit der Abwicklung das KSH beauftragte und den 28. Februar als „ideellen Zeitpunkt” bestimmte. ${ }^{5}$ Aber nicht nur politische, sondern auch fachliche Argumente haben die Aufnahme unterstützt. Gyula Konkoly-Thege - der in diesen Zeiten als der bedeutendste Agrarstatistiker betrachtet werden kann und ab 1936 den Posten des Präsidenten von dem KSH innehatte rechtfertigte die unaufschiebbare Notwendigkeit des Zensus in einem Artikel vom Februar 1935 von „Statisztikai Szemle” mit den folgenden Ursachen: 1. Seit der Bodenreform tappen wir im Dunkeln bezüglich der Zahl, Ausstattung und des Zustandes der Betriebe. 2. Die Ansiedlung machte die Frage auch aktuell. 3. Die Intensität muss gesteigert werden, aber dazu braucht man einen Stützpunkt. Konkoly-Thege schliesst seine Beweisführung mit der Folgerung, dass die Schwere der Vermarktungslage nur so beurteilt werden kann, wenn unsere Ergebnisse zu internationalen Angaben gemessen werden, was ebenfalls korrekte Indexe voraussetzt. ${ }^{6}$

Der Vergleich ist hier auch wichtig! Vor dem Zensus von 1935 gab es zuletzt im Jahre 1895 eine ähnliche Aufnahme, was nach vierzig Jahren bedeutet! In der heutigen Statistik, in der alle 10 Jahre ein Agrarzensus organisiert wird, sind konsistentere Gleichstellungen möglich. Frau

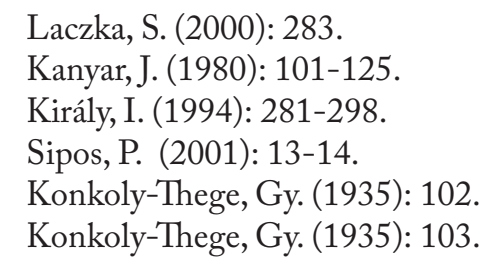


Lacka hat zwar den Zensus von 1895 nach der Abwicklung und Bearbeitung als ein Meisterwerk beurteilt, aber die Angaben haben ihre imformierenden Aspekte bis zu den Dreißigerjahren verloren. ${ }^{7}$ Trotzdem baute diese Gleichsetzung in der späteren Geschichtsschreibung auf eine ganze Reihe der Werke auf, obwohl in vielen Fällen mit methodologischen Unterschieden $\mathrm{zu}$ rechnen ist. Der Vergleich mit dem Zustand der vorherigen vierzig Jahre scheint noch im Falle der Anzahl der Agrarbetriebe und der landwirtschaftlichen Nutzflächen (LNF) das Relevanteste zu sein. ${ }^{8}$ Während ein solcher Vergleich im Fall der Landtechnik und Arbeitskraft schon zu bezweifeln ist. Obwohl es einigermaßen doch belegt werden kann, wenn wir uns auf die jährlich wiederkehrenden Datensammlungen der Agrarstatistik stützen, dessen Reorganisation inzwischen stufenweise in Gang gesetzt worden ist. ${ }^{9}$

\section{Somogy, das von Großgrundbesitzen beherrschte Komitat}

Warum ist dieses, zwischen Balaton und Drau liegende, südtransdanubische Komitat so interessant? Fangen wir zuerst mit sozialhistorischen Aspekten an! Es muss vorweggenommen werden, dass sich die damaligen Komitatsgrenzen von den heutigen teilweise unterschieden: während die Umgebung von Szigetvár hierher gehörte, fiel Siófok außerhalb jener. Der Gebietsbestand ist hier - gegenüber Baranya - durch das Friedensdiktat nicht geschrumpft. Nach den Angaben der Volkszählung aus dem Jahre 1930 betrug die Population in Somogy - auf beinahe $6700 \mathrm{~km}^{2}-385635$ Personen. Innerhalb dessen war der Anteil der landwirtschaftlichen Bölkerung 69,1\%, dies überschritt auf nationaler Ebene den registrierten Durchschnitt von $51,5 \% .^{10}$

Hinsichtlich des Komitats wird oft hervorgehoben, dass es - neben Fejér - die Landschaft ist, die am meisten von Großgrundbesitzen dominiert war, welches Attribut Trianon noch mehr vergrößert hat. Währenddessen ist der Agrarierflügel von Somogy - der vorher hinter Komitat Pest, Siebenbürgen und Westungarn in die zweite Linie gedrückt war - infolge des Friedensdiktats in den Vordergrund gerückt. Die erhöhte Bedeutung dieser Gruppe wurde auch dadurch bewiesen, dass sich viele hiesige Prominente landesweit an die Spitzen der Agrarinteressenverbände geschoben hatten. So kam zum Beispiel GrafMiksa Hoyosinden Vorsitz der Landwirtschaftskammer für Ungarn, Graf László Somssich in den Landwirtschaftsverein für Ungarn (OMGE). Letztere war ausgesprochen die Lobby des Großfgrundbesitzes. Die im Jahre 1930 neugegründete oppositionelle Kleinwirtenpartei (FKGP) wählte mit Gaszton Gaál auch einen Somogyer Großgrundbesitzer zu ihrem Anführer.

Wiewieit spiegeln die Angaben des Zensus den Charakter des Großgrundbesitzes wieder? Derzeit machte der Anteil der Großbetriebe über 1000 Joch im Komitat 38,5\% aus. Größere Werte als diese wurden in den Komitaten Fejér und Komárom-Esztergom mit 41,3\%, bzw. 38,9\% registriert. Die Minderung des Großgrundbesitzes kann auch in Somogy festgestellt werden, da diese Kategorie noch im Jahre 1895 einen Anteil von 58,9\% betrug. ${ }^{11}$

Laczka, S. (2000): 282.

8 Aber hier ist es auch ein Problem, dass während die öffentlichen Weiden, Wälder und sonstigen Flächen aus der Betriebsstatistik vom Jahre 1895 ausblieben, wurden sie von der Aufnahne vom Jahre 1935 enthalten.

9 Konkoly-Thege, Gy. (1935): 102.

10 Népszámlálás (1930. II.): 46*.

11 Földbirtok (1935. I.): 12*-13*.; Gazdaságok (1895): 25. 
Abbildungen 1-2. Grundbesitzstruktur von Somogy im Jahre 1935

a.) Verteilung der Betriebe, \%

Gesamtfläche, Joch

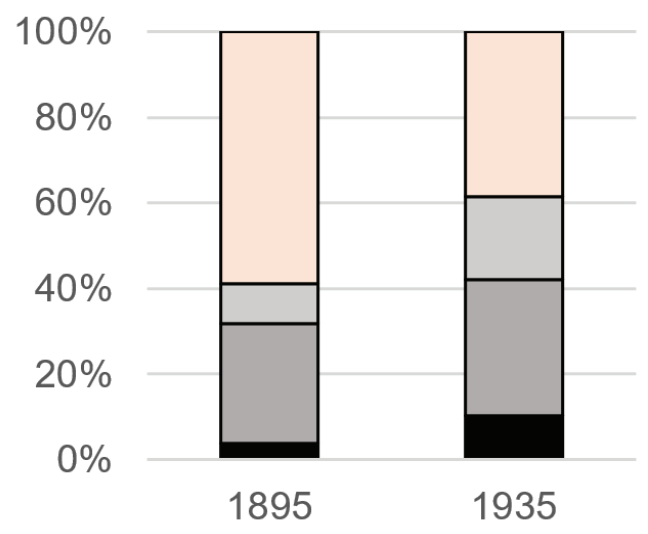

-unter 5 Joch $\quad$ व5-100 Joch

口100-1000 Joch aüber 1000 Joch
Gesamtzahl der Betriebe

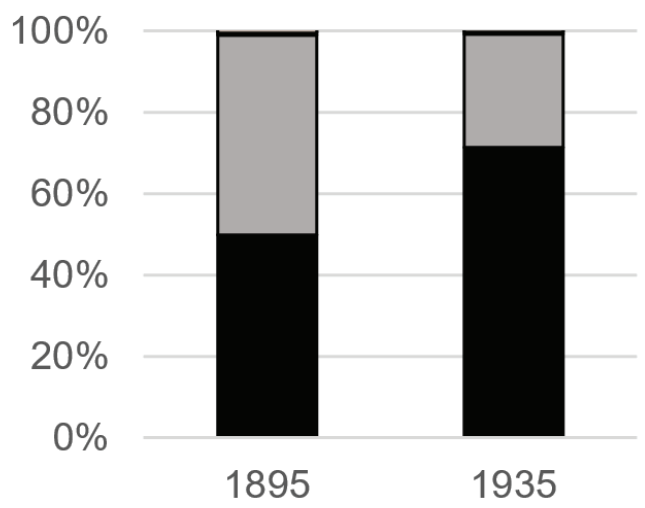

שunter 5 Joch $\quad$ 口5-100 Joch

口100-1000 Joch über 1000 Joch

b.) Verteilung der Pachtungen, \%

Gesamtfläche, Joch

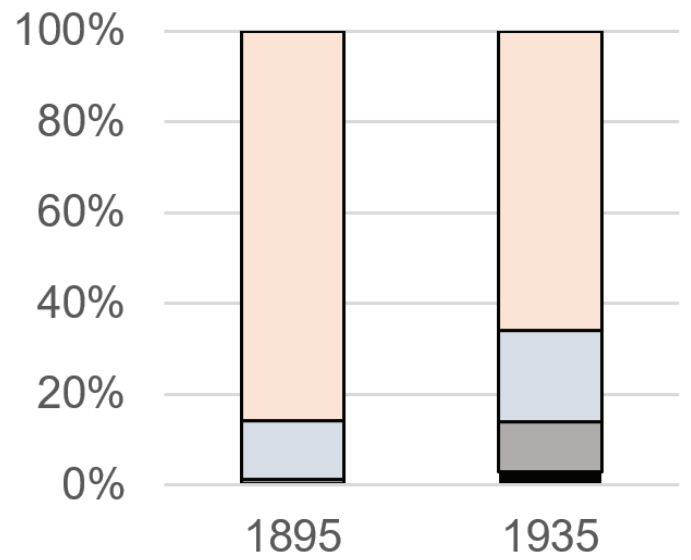

unter 5 Joch

口5-100 Joch

100-1000 Joch 口über 1000 Joch
Gesamtzahl der Betriebe

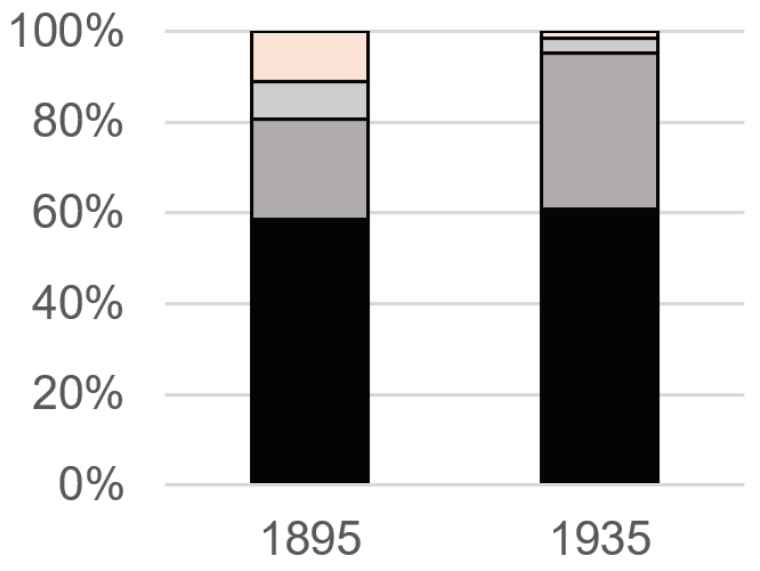

שunter 5 Joch $\quad$ 口5-100 Joch

口100-1000 Joch über 1000 Joch

Quelle: Forrás: Földbirtok (1935. I.): 44-67.

Aber der Rückgang der Großgrundbesitze kann grundlegend nicht auf die Auswirkungen der Bodenreform von 1920 zurückgeführt werden - die nur 6,1\% der Fläche berührte, was dem nationalen Durchschnitt unterlegen war, - sondern auf die Parzellierungen, d. h. Markthandlungen. Zwischen 1895 und 1935 hat das Gewicht aller kleinen Kategorien - unter dem Großgrundbesitz - zugenommen. Der größte Anstieg war in den Zwergbetrieben unter 5 Joch zu registrieren. Diese beteiligten sich im Jahr 1935 am Gebiet des Komitats mit 10,3\%, während die Kleinbetriebe zwischen 5 und 100 Joch ein Drittel und die Mittelbetriebe zwischen 100 und 1000 Joch ein weiteres Fünftel von jenem eingenommen haben. ${ }^{12}$ 
Worum es wenig gehandelt ist, ist es das Vordringen der Kleinpachtungen. Im Wesentlichen wollte man damit die eingeschränkte Bodenreform kompensieren. Während sich 85,9\% der verpachteten Fläche von 1895 in den Händen von Großpächtern konzentriert hat, hat sich dieser Anteil bis 1935 auf 65,9\% verringert. Man muss sagen, dass sich das Gewicht kleinerer Kategorien hier auch erhöht hat. Dieses Vordrigen war in der Kategorie zwischen 5 und 100 Joch das Sichtbarste. Aber den meisten Pächtern - ungefähr 61\% - gehörte weiterhin weniger als 5 Joch. ${ }^{13}$

Neben den Kleinpachtungen ist hier das Maß der Bodenreform und - in der GömbösÄra - der Anteil der „geschützten Güter” von Interesse. Um es zu schildern, fertigte ich solche thematische Karten an, in welchen ich die Streuung dieser Kategorien in Ortschaften des Komitats verfolgen konnte.

\section{Karten 1-4. Die ortschaftlichen Aspekte der Bodenpolitik in Somogy}

a.) Großgrundbesitze über 1000 Joch

b.) Bodenreformfelder
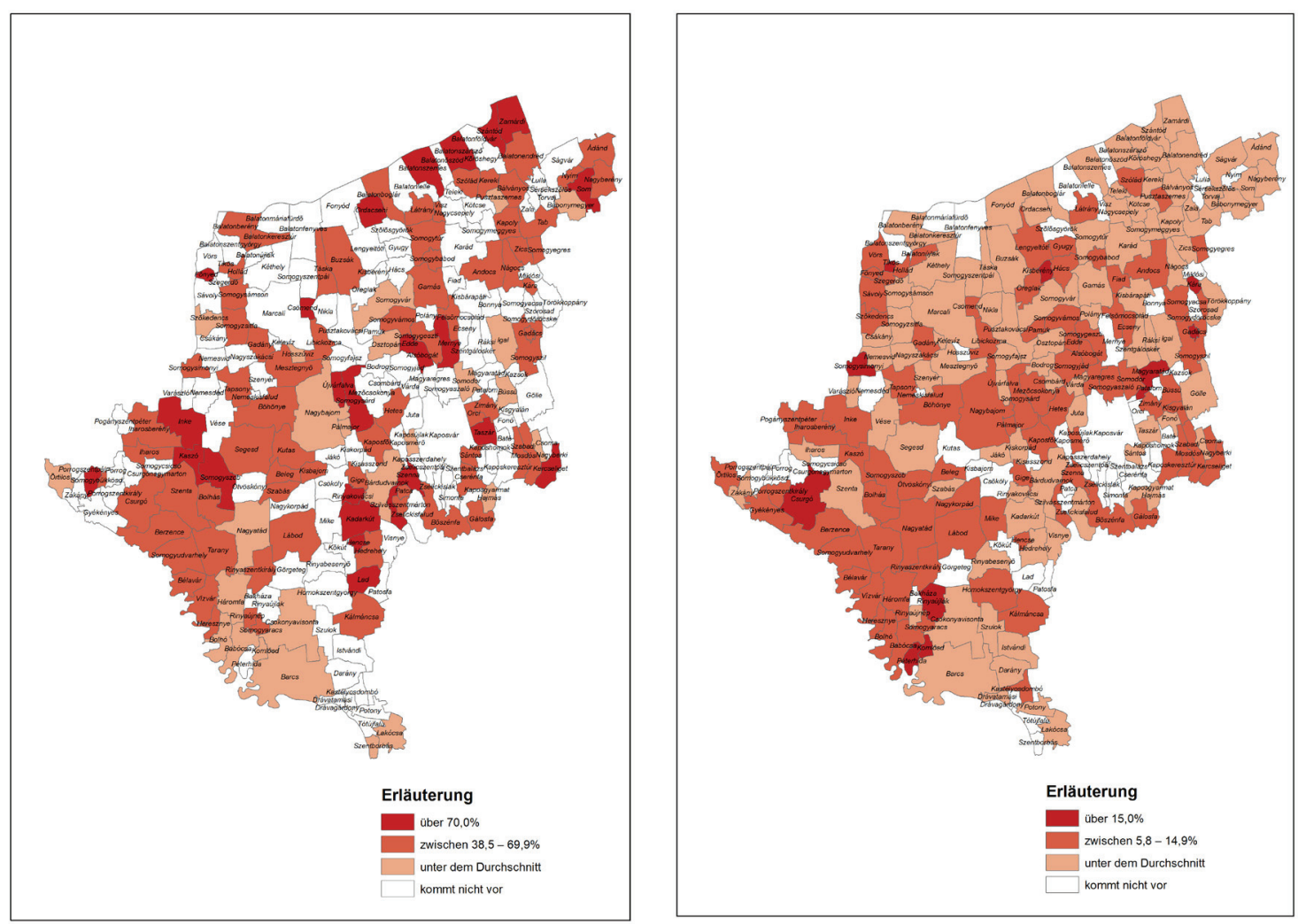

13 Ders. 


\section{Karten 1-4. Die ortschaftlichen Aspekte der Bodenpolitik in Somogy (Fortsetzung)}

c.) Kleinpachtungen unter 100 Joch

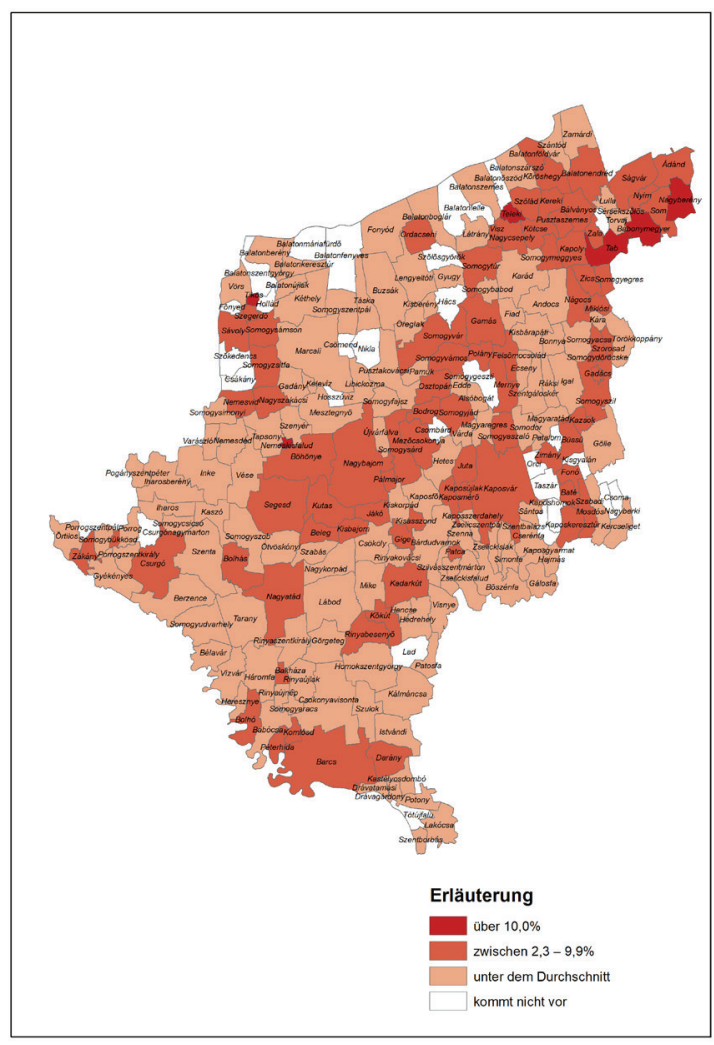

d.) „Geschützte Güter”

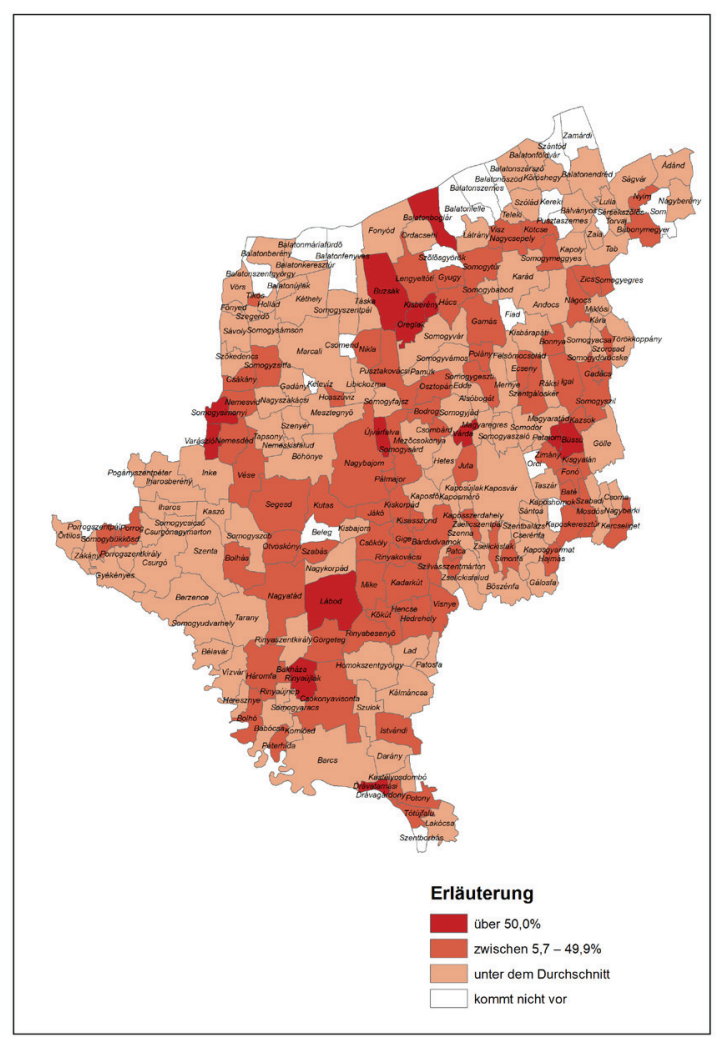

Quelle: Földbirtok (1935. I.): 44-67.

Aber es ist notwendig mit den Großgrundbesitzen über 1000 Joch anzufangen! Der gebietliche Anteil dieser Kategorie war in den Siedlungen der Umgebung von Csurgó, Nagyatád, Lengyeltóti und Marcali das Größte. Hier nahmen die Großgrundbesitze mehr, als 70\% der Fläche ein. Es ist kein Zufall, dass es sich um diejenigen Kreise handelte, in denen man in der Bodenreform am weitesten vorkam, dessen Maß an vielen Orten hoch über 15\% lag. Mit den Kleinpachtungen konnte man vor allem in den Kreisen von Tab und Igal rechnen, wo viele Kirchengüter vorhanden waren. Die Kleinpachtungen unter 100 Joch dehnten sich hier vielerorts auf mehr als 10\% der Fläche aus. Die meisten „geschützten Güter”waren bei Kaposvár und Szigetvár zu finden, nicht selten mit einem gebietlichen Anteil von mehr als 50\%. ${ }^{14}$

\section{Krisenbekämpfung, „Mehrproduktion”, Minderung des Getreideübergewichtes}

Mit der Agrarkomponente der Wirtschaftskrise hat es auf internationaler Ebene schon im Jahre 1928 angefangen, was in 1933 zu Ende kam. Dem gegenüber kamen die ersten Anzeichen der industriellen Krise im Jahre 1930 zum Vorschein und die Absatzschwierigkeiten lösten sich erst in 1937. ${ }^{15}$ Der Starökonom dieser Epoche Mátyás Matolcsy schrieb auch, dass sich der Zustand der landwirtschaftlichen Bevölkerung zwischen 1929 und 1933 verschlechterte. Während er sich im Zeitraum zwischen 1934 und 1938 stufenweise verbessert hat. ${ }^{16}$ Also ging es im Jahre

14 Földbirtok (1935. I.): 44-67.

15 Borsányi, Gy. (1986): 13.

16 Matolcsy, Gy. (1944): 29-53. 
1935 in Ungarn mit der Agrarkrise schon abwärts. Mit der Intensität - die mit dem Ausweg der Krise identisch war - beschäftigte sich ein Sonderband des Zensus von 1935. Was ist darunter zu verstehen? Vor allem Landtechnik - darunter Vierrad-, und Kettenschlepper -, Viehbestände, organische und künstliche Düngung und nicht zuletzt Obst- und Gemüsenplantagen. Obwohl Somogy hinsichtlich der meisten spezifischen - gebietseinheitlichen - Indexe den nationalen Durchschnitt überstieg, lag es im allgemeinen doch unter den transdanubischen Werten.

Tafel 1. Die wichtigen Indexe der Intensität in den Komitaten, 1935

\begin{tabular}{|c|c|c|c|c|c|c|}
\hline \multirow{5}{*}{ Komitaten/Regionen } & \multicolumn{6}{|c|}{ Auf } \\
\hline & \multicolumn{4}{|c|}{100 Joch } & \multicolumn{2}{|c|}{10000 Joch } \\
\hline & \multicolumn{6}{|c|}{ LNF entfallen } \\
\hline & $\begin{array}{l}\text { Rind- } \\
\text { vieh }\end{array}$ & Pferde & Schweine & $\begin{array}{l}\text { Obst- } \\
\text { bäume }\end{array}$ & $\begin{array}{l}\text { Trak- } \\
\text { toren }\end{array}$ & \multirow[t]{2}{*}{$\begin{array}{l}\text { gedüngte } \\
\text { Fläche, Joch }\end{array}$} \\
\hline & \multicolumn{5}{|c|}{ Stücke } & \\
\hline Baranya & 18 & 9 & 49 & 295 & 4 & 1700 \\
\hline Fejér & 15 & 6 & 46 & 294 & 7 & 2532 \\
\hline Győr, Moson és Pozsony & 20 & 6 & 40 & 213 & 7 & 2638 \\
\hline Komárom és Esztergom & 14 & 7 & 35 & 242 & 5 & 2417 \\
\hline Somogy & 17 & 8 & 43 & 254 & 6 & 1835 \\
\hline Sopron & 29 & 7 & 39 & 250 & 7 & 2185 \\
\hline Tolna & 17 & 8 & 50 & 238 & 6 & 2096 \\
\hline Vas & 28 & 4 & 32 & 283 & 5 & 2084 \\
\hline Veszprém & 19 & 5 & 36 & 165 & 6 & 1911 \\
\hline Zala & 23 & 5 & 33 & 318 & 3 & 1448 \\
\hline Transdanubien & 19 & 7 & 41 & 259 & 6 & 2019 \\
\hline Tiefebene & 11 & 7 & 34 & 269 & 5 & 1659 \\
\hline Norden & 15 & 6 & 25 & 250 & 6 & 1603 \\
\hline Insgesamt & 15 & 7 & 36 & 263 & 5 & 1785 \\
\hline
\end{tabular}

Quelle: Földbirtok (1935. I.): 66-103.; Üzemi adatok (1935. II.): 142-161.

Diese Hinweise wurden von Albert Kiss, dem damaligen jungen technischen Hochschulprofessor in einer - ebenfalls auf die Angaben der Konskription von 1935 basierende - Studie analysiert. Nach diesen Zahlen erhöhte sich die Maschinendichte zwischen den zwei Zensus im Komitat in den meisten Kategorien und innerhalb der Viehbestände kam der Rassenwechsel zu Ende, der die Nutztiere - also Milchkühe, Fleischschweine, kaltblütige Pferde - in den Vordergrund stellte. Während die Plantagen auch ein größeres Gewicht im Vergleich zu den früheren Zeiten vertraten, wo sich der Schwerpunkt gegen die Apfelproduktion verschoben hat. ${ }^{17}$ Am Ende des 19. Jahrhunderts war in diesem Wirtschaftszweig - dank der Tätigkeit von Graf Imre Széchenyi - das Weingebiet von Süd-Balaton noch das Bedeutendste. 
Abbildung 3. Rassenwechsel in den Viehbeständen von Somogy

a.) Verteilung der Rinder, $\%$

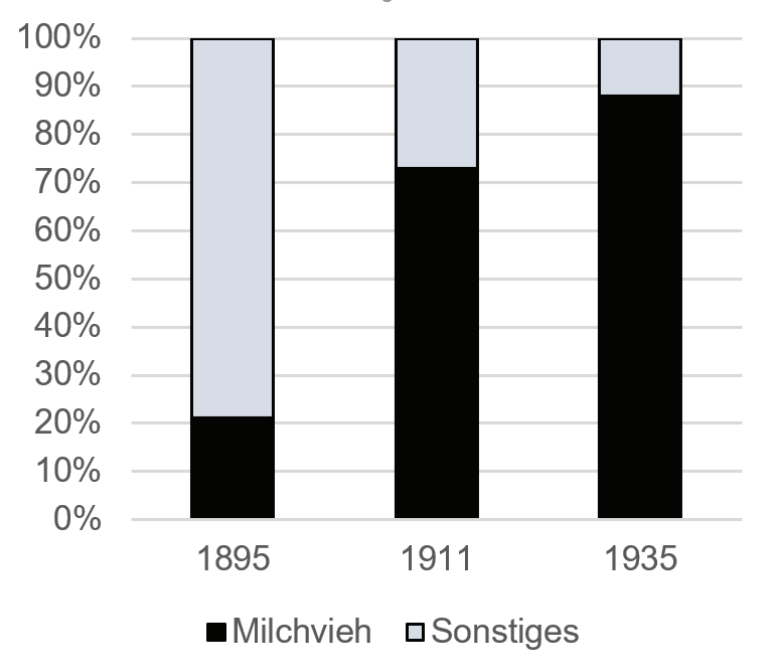

b.) Verteilung der Schweine, \%

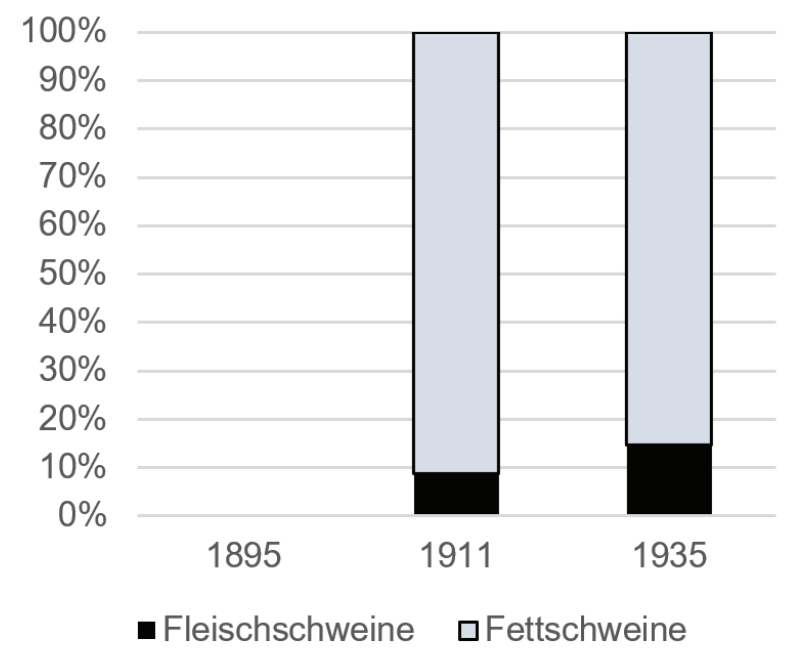

Quelle: Kiss, A. (1944): 48-57.

Aber die Intensität an sich war zu wenig, dazu mussten noch die Elemente der volkswirtschaftlichen Planmäßigkeit beitragen. Es benötigte die Abgrenzung der Tätigkeiten zwischen den Groß- und Kleinbetrieben, deren Wurzeln bis zur Zeit der Bodenreform zurückgehen, als es die größte Anforderung die Sicherung des gesellschaftlichen Friedens bedeutete. Zoltán Koós, der in Landproblem maßgebende Bankier - später Generaldirektor der Ungarischen Bodenkreditianstalt - in einer damaligen Studie ging davon aus, dass die verschiedenen Produktionszweige verschiedenen Betriebstypen entsprechen. ${ }^{18}$ Der Großbetrieb sollte in jenen Zweigen vorteilhaft sein, wo große Investitionen und sorgfältige Bodenbearbeitung erforderlich sind, wie zum Beispiel bei den Industriepflanzen. In der Viehzucht rückten die Vorteile der großen Organisationen dort in den Vordergrund, wo die veterinären Vorschriften einzuhalten waren und die richtige Fütterung und die gebildete Arbeitskraft eine große Rolle spielten, dessen typisches Feld die Mästung ist. Dem gegenüber ging der Kleinbetrieb dem Großgrundbesitz in den arbeitsintensiven Zweigen, wie zum Beispiel in der Obst- und Gemüseproduktion über. In der Viehzucht kommt dieser Typ dort in Frage, wo sich die obige Ansichten weniger durchsetzten. Solche Zweige sind die Milch- und Eierproduktion und die Geflügelzucht. In den Dreißigerjahren machte die Wirtschaftskrise das Anpassen an die Bedingungen noch wichtiger. Es wurde die Arbeitsverteilung und die Kooperation zwischen den Groß- und Kleinbetrieben vielmehr nötig.

Es ist fraglich, wieviel davon in Somogy bis zum Frühling 1935 realisiert wurde? Man kann nur soviel sagen, dass das soziale Verantwortungsgefühl der Großgrundbesitzer zu dieser Zeit wesentlich zugenommen hat. Immer mehr Besitzer nahmen die Bewirtschaftung in die eigenen Hände, nicht nur auf den kirchlichen, sondern auch auf den weltlichen Gütern. Zoltán Kaposi, der die damaligen Somogyer Großgrundbesitze in vielen seinen Monographien aufarbeitete, hebt in dieser Hinsicht die Biedermanns von Szentegát hervor. ${ }^{19}$ Aber es gehört zu dieser Reihe auch das Gut von László Somssich in Kaposújlak. ${ }^{20}$ Diese Mustergüter waren die Vorkämpfer jener Koordinierung, die die Verbesserung der Wirtschaftsmethoden im Kreis der Kleinbetriebe erzielte.

18 Koós, Z. (1921): 368-388.

19 Kaposi, Z. (2019): 101-122.

20 Scherer, P. (1939): 398-402. 
Abbildung 4. Komplementarität zwischen Groß- und Kleinbetriebe in Somogy, 1935

a.) Saatflächenstruktur, $\%$

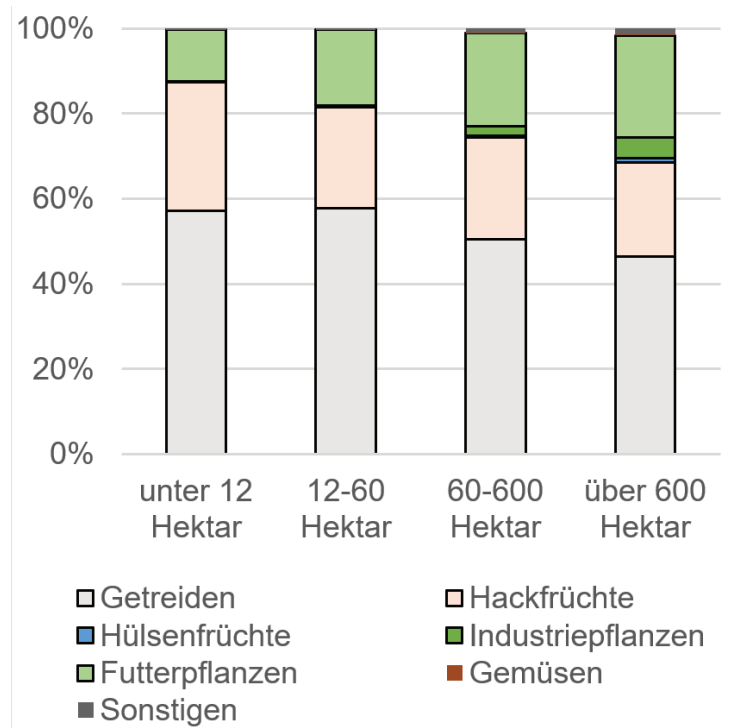

b.) Zusammensetzug des Viehstands, \%

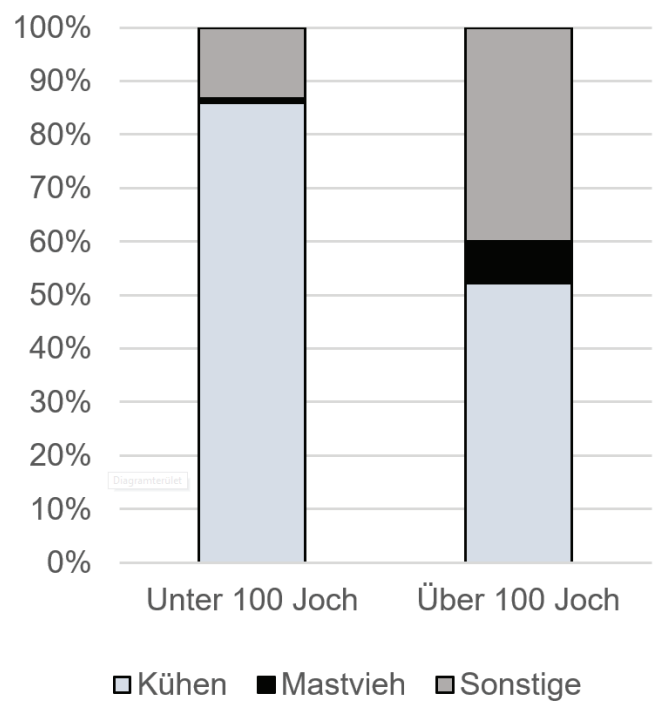

Quelle: Történeti Statisztikai Kötetek (1934-1945): 63.; Kiss, A. (1944): 52-71.

Aber wie schaute es in dem Komitat aus? Nehmen wir zum Beispiel die Unterschiede der Saatflächenstruktur! Wenn wir von den kleinen gegen die großen Einheiten vorangehen, sehen wir, dass sich der Anteil der Getreide und Hackfrüchte (Mais, Kartoffel) immer mehr verminderte. Während sich die Proportion der Futter-, und Industriepflanzen, Hülsenfrüchte und Gemüse stufenweise erhöhte. Die Richtung der Rinderhaltung unterschied sich auch in den Groß- und Kleinbetrieben, obwohl die Ergänzungstendenzen zwischen den zwei Kreisen auch nachgewiesen werden können. Die Zusammensetzung der beiden Viehstände wurde von Albert Kiss geprüft, der die Angaben zu den Ergebnissen der Tierzählung von 1895 verglichen hat. Nach diesen Aufnahmen war der Anteil der Kühe in beiden Zeitpunkten in den Betrieben unter 100 Joch besonders hoch. Während die Betriebe über 100 Joch über einen stattlichen Mastviehbestand verfügten. Bis 1935 hat sich das Verhältnis der Kühe in den beiden Gruppen erhöht, jener der Mastrinder bei den großen verringert, bei den kleinen gesteigert. ${ }^{21}$ Am Ende der Dreißigerjahre hat József Nádujfalvy, der soziale Berater vom Komitat in Somogy die beispielgebende Rolle des Großgrundbesitzes im Feld der Viehzucht für wichtig gehalten. ${ }^{22}$

\section{Zusammenfassung}

Der Agrarzensus von 1935 war der Eerste, der im Zusammenhang eines internationalen Kontexts abgewickelt wurde. Diese Aufnahme deutete gleichzeitig auf die rückständigen Verhältnisse der damaligen ungarischen Landwirtschaft hin. Somogy nahm hier eine Mittelposition in der nationalen Rangliste ein. Die Angaben und die Analyse von Albert Kiss bewiesen, dass das Streben nach der Selbstversorgung derzeit - gegenüber den ökonomischen Überlegungen noch nicht ganz ausgeschaltet werden konnte.

Infolge der Krise rückten die Intensivierung und die Kooperation der Groß- und Kleinbetriebe auch hier in den Vordergrund. Dazu wurden die geeigneten Rahmen vor allem von den - fachliche Beförderung und zugleich eine Interessenvertretung bietenden Kammern versichert. Die Aufstellung dieser Organe auf territorialem Grund wurde schon von

21 Kiss, A. (1944): 57-71.

22 Nádujfalvy, J. (1939): 85-92. 
der Urkleinwirtenpartei, der Nagyatádi-Partei in ihrem Program von Szentgál im Jahre 1909 gefordert.Dieser Wunsch wurde nach dem ersten Weltkrieg wahr, als die Landwirtschaftskammer für Untertransdanubien im Jahre 1920 gegründet wurde. Dieses Organ hatte seinen Sitz in Kaposvár, dessen räumlicher Geltungsbereich - neben Baranya, Somogy, Tolna - sich auch auf Zala ausdehnte. ${ }^{23}$ Wie es sich aus der damaligen Lokalpresse herausstellte, hat die Kammer an der Krisenbekämpfung aktiv mitgewirkt und - rückbestätigend die zentralen Fragen des Zensus - den Aufschwung der Geflügel-, und Schweinezucht, bzw. des Plantagenanbaues angeregt. In diesem Zusammenhang schrieb man von einem in Kaposvár zu errichtenden Schlachthof. Aber der Erretter wurde überraschenderweise nicht in dem deutschen Markt gesehen, sondern es wurde eher den englischen Importeuren und Investoren zugetraut. ${ }^{24}$

Schließlich das Thema mit den Augen des Historiker zu betrachten: der Vergleich zu den Angaben der vorherigen vierzig Jahre muss aus sozialhistorischen Ansichten auch überlegt werden. Péter Gunst schrieb, dass sich die Agrargesellschaft bis zu den Dreißigerjahren im Vergleich zu dem Dualismus in bedeutendem Ausma $\beta$ umgewandelt hat. Während gewisse landwirtschaftlichen Arbeiterschichten zu existieren aufhörten, oder sich in Anzahl verminderten, wurde insgesamt eine abwärts haltende Nivellierung beobachtet. ${ }^{25}$

\section{Bibliographie}

Borsányi, Gy. (1986): Válságévek krónikája, 1929-1933: az 1929-1933-as gazdasági válság hatása Magyarországon. Budapest

Gergely,J.Hrsg. (2004): Antal István sajtófönök emlékiratai. Gömbös Gyula hatalomra kerüléseés kormányzása 1932-1936. Budapest

Gunst, P. (1998): A magyar agrártársadalom 1919-1945 között, in: Gunst Péter, A magyar agrártársadalom a jobbágyfelszabaditástól napjaink. Budapest

Kaposi,Z.(2013): A nagybirtok, mint búnbak. Azuradalmakés az agrárszegénység kapcsolata Magyarországon. in: Gyarmati György-Lengvári István-Pók Attila-Vonyó József: Bünbak minden időben. Pécs-Budapest Kaposi, Z. (2001): A magyarországi nagybirtok-rendszer változásai (1700-1945), Somogy megye múltjából. Levéltári évkönyv 32. (2001) 95-120. Kaposvár

Kaposi, Z. (2019): Uradalmak, földbirtokosok, birtokforgalom a Dél-Dunántúlon a 19. században. Budapest Kaposi,Z.(2000): Uradalmi gazdaságés társadalom a 18-19. században:A vrászlói társadalom átalakulásának folyamata. Budapest-Pécs

Kaposi, Z. (2019): Bécstôl Szentegátig. A Biedermann família uradalmai a Dél-Dunántúlon (1849-1914), Közép-Európai Közlemények 44. (2019) 1. 101-122.

Kanyar, J. (1980): Somogy megye agrártársadalma az elsôf foldreformtól a szocialista mezốgazdaságig (19201949). Budapest

Király, I. (1975): A második világháborút követó iparpolitikai törekvések és annak történeti elózményei Somogyban, Somogy megye múltjából. Levéltári évkönyv 6. (1975) 193-222.

Király, I. (1994): A mezốgazdaság technikai fejlödése a két világháború között Magyarországon. Somogy megye múltjából. Levéltári évkönyv 25. (1994) 281-298. Kaposvár

Király, I. Sz. (2013): A magyar mezögazdaság gépesitésének mültja: a kezdetektöl 1989-ig. Kaposvár

Király, I. (2004): A Dél-Dunántúl mezógazdasága és állattenyésztése 1848-1944. Kaposvár

Király, I. (1963): A szarvasmarbatenyésztés átalakulása Somogy megyében 1848-1944, Agrártörténeti Szemle 5. (1963.) 1-2.177-210.

Kiss, A. (1944): Mezógazdaságunk fejlódése 1895-1935. Statisztikai tanulmány. Budapest

23 Laut des Gesetzes XVIII. von 1920 über die landwirtschaftlichen Interessenvertretung.

24 Die Nummern von „Somogyi Ujság” aus den Jahren 1930-1936.

25 Gunst, P. (1998): 233-248. 
Konkoly-Thege, Gy. (1935): A földbirtokok és üzemek statisztikai összeirása. Statisztikai Szemle 13. (1935) 5.101-108.

Koós, Z. (1921): A földbirtokreform. Közgazdasági Szemle 63. (1921) 1-4. 368-388.

Laczka, S. (2000): Mezógazdasági összeírások Magyarországon 1895-2000. Statisztikai Szemle 78. (2000) 4. 282-289.

Matolcsy, M. (1944): Az életszinvonal alakulása Magyarországon, 1924-1944. Budapest. 29-53.

Milotay, I. (1930): Az ismeretlen Magyarország. Budapest

Nádujfalvy, J. (1939): Somogymegye szociális és gazdasági helyzetképe: A népesség, terület és életviszonyok módszeres vizsgálata. Kaposvár

Scherer, P. (1939): A nagybirtok. Budapest

Sipos, P. (2001): Imrédy Béla. (Politikai életrajz.) Budapest

Thassy, J. (1996): Veszélyes vidék. Budapest

\section{Quellen und angegebene Statistiken}

Népszámlálás (1930. II.): Az 1930. évi népszámlálás. 2. r. Foglalkozási adatok községek és külterületi lakotthelyek szerint, továbbá az ipari és kereskedelmi nagyvállalatok. Budapest. KSH, 1934

Agrárcenzus (1895): A Magyar Korona országainak mezógazdasági statisztikája. 1. r. A magyar statisztika fejlódése az 1895. évi VIII. törvényczikk alapjän végrehajtott összeiraás föbb eredményei községenkint. Budapest. KSH, 1897

Mezőgazdasági termelés (1895): A Magyar Korona országainak mezógazdasági statisztikája. 2. r. Mezógazdasági termelés 1895. és 1896. évben. Budapest. KSH, 1897

Gazdaságok (1895): A Magyar Korona országainak mezógazdasági statisztikája. 3. r. A gazdaságok megoszlása jelleg és nagyság szerint. Budapest. KSH, 1900

Végeredmények (1895): A Magyar Korona országainak mezôgazdasági statisztikája. 4. r. Végeredmények: 17 grafikai térképpel. Budapest. KSH, 1900

Földbirtok (1935. I.): Magyarország földbirtokviszonyai az 1935. évben. I. Törvényhatóságok és községek (városok) szerint. Budapest. KSH, 1936

Földbirtok (1935. II.): Magyarországföldbirtokviszonyai az 1935. évben. II. Birtoknagyságcsoportok szerint. Budapest. KSH, 1937

Állatok, gépek, gyümölcsfák (1935): Magyarország állatállománya, gazdasági gépfelszerelése és gyümölcsfaállománya az 1935. évben. Törvényhatóságok és községek (városok) szerint. Budapest. KSH, 1937 Üzemi adatok (1935. I.): Magyarország mezögazdaságának föbb üzemi adatai az 1935. évben. II. Törvényhatóságok és községek (városok) szerint. Budapest. KSH, 1938

Üzemi adatok (1935. II.): Magyarország mezögazdaságának föbb üzemi adatai az 1935. évben a gazdaságok (üzemek)nagysága szerint. Budapest. KSH, 1941

Történeti Statisztikai Kötetek (1934-1945): Növénytermelés: Megyei adatok, 1934-1945, Budapest. SKV, 1984 